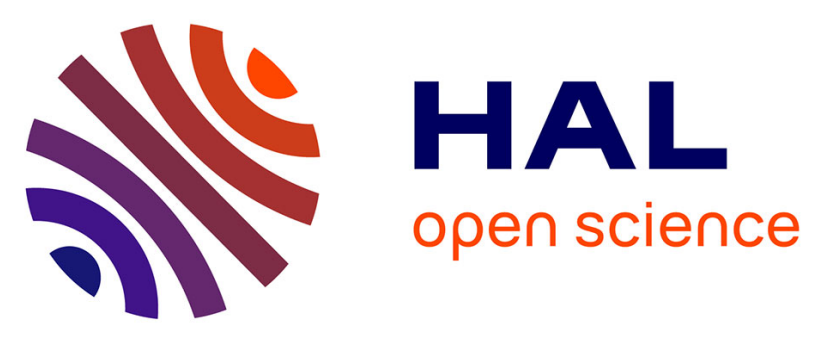

\title{
First characterisation of the populations and immune-related activities of hemocytes from two edible gastropod species, the disk abalone, Haliotis discus discus and the spiny top shell, Turbo cornutus.
}

Ludovic Donaghy, Hyun-Ki Hong, Christophe Lambert, Heung-Sik Park, Won Joon Shim, Kwang-Sik Choi

\section{To cite this version:}

Ludovic Donaghy, Hyun-Ki Hong, Christophe Lambert, Heung-Sik Park, Won Joon Shim, et al.. First characterisation of the populations and immune-related activities of hemocytes from two edible gastropod species, the disk abalone, Haliotis discus discus and the spiny top shell, Turbo cornutus.. Fish and Shellfish Immunology, 2010, 28 (1), pp.87-97. 10.1016/j.fsi.2009.10.006 . hal-00460531

\section{HAL Id: hal-00460531 \\ https://hal.science/hal-00460531}

Submitted on 1 Mar 2010

HAL is a multi-disciplinary open access archive for the deposit and dissemination of scientific research documents, whether they are published or not. The documents may come from teaching and research institutions in France or abroad, or from public or private research centers.
L'archive ouverte pluridisciplinaire HAL, est destinée au dépôt et à la diffusion de documents scientifiques de niveau recherche, publiés ou non, émanant des établissements d'enseignement et de recherche français ou étrangers, des laboratoires publics ou privés. 


\title{
First characterisation of the populations and immune-related activities of hemocytes from two edible gastropod species, the disk abalone, Haliotis discus discus and the spiny top shell, Turbo cornutus.
}

\author{
Ludovic Donaghy, ${ }^{a, b,}$, Hyun-Ki Hong ${ }^{a}$, Christophe Lambert ${ }^{b}$, Heung-Sik Park ${ }^{c}$, Won Joon Shim ${ }^{d}$, \\ Kwang-Sik Choi ${ }^{\mathrm{a}}$.
}

${ }^{a}$ : School of Applied Marine Life Sciences (POST BK-21) and Marine and Environment Research Institute, Jeju National University, 66 Jejudaehakno, Jeju 690-756, Republic of Korea

b : LEMAR CNRS UMR 6539, IUEM, Université de Bretagne Occidentale, Place Nicolas Copernic, Technopôle Brest-Iroise, 29280 Plouzané, France

c : Marine Living Ressources Research Division, Korea Ocean Research and Development Institute, Ansan, Republic of Korea

${ }^{d}$ : South Sea Institute, Korea Ocean Research and Development Institute, Geoje, Republic of Korea

\begin{abstract}
The disk abalone Haliotis discus discus and the spiny top shell Turbo cornutus are edible gastropod species of high economic value, mainly in Asia. Mortality outbreaks and variations in worldwide stock abundance have been reported and suggested to be associated, at least in part, with pathogenic infections. Ecology, biology and immunology of both species are currently not well documented. The characterisation of the immune systems of these species is necessary to further assess the responses of $H$. discus discus and $T$. cornutus to environmental, chemical and disease stresses. In the present study, we investigated the morphology and immune-related activities of hemocytes in both species using light microscopy and flow cytometry. Two types of hemocytes were identified in the disk abalone hemolymph, blast-like cells and hyalinocytes; whereas four main hemocyte types were distinguished in the spiny top shell, blast-like cells, type I and II hyalinocytes, and granulocytes. Flow cytometric analysis also revealed differences between cell types in immunerelated activities. Three subsets of hemocytes, defined by differing lysosomal characteristics, were observed in the hemolymph of the spiny top shell, and only one in the disk abalone. Phagocytic activity was higher in $H$. discus discus hemocytes than in $T$. cornutus hemocytes, and the kinetics of PMA-stimulated oxidative activity was different between hemocytes of the disk abalone and the spiny top shell. Finally our results suggest for the first time a predominant mitochondrial origin of oxidative activity in gastropod hemocytes.
\end{abstract}

* Corresponding author at : LEMAR CNRS UMR 6539, IUEM, Université de Bretagne Occidentale, Place Nicolas Copernic, Technopôle Brest-Iroise, 29280 Plouzané, France. Tel.: +33 2984986 44; fax: +33 2984986 45. E-mail address: ludovic.donaghy@gmail.com (L. Donaghy).

Keywords: Disk abalone ; Spiny top shell ; Hemocytes ; Flow cytometry ; Phagocytosis ; Oxidative activity ; Lysosomes

\section{Introduction}

Homeostasis in molluscs partially relies upon cells freely circulating in hemolymph and infiltrating in tissues, referred to as hemocytes [1-3]. Hemocytes are involved in various and numerous physiological functions including nutrient digestion, transportation, and distribution [4-6], and shell and tissue repair [7-9]. Hemocytes also mediate cellular internal defence in molluscs through accumulation and detoxification of chemical toxicants [10-12], phagocytosis [13-18] and encapsulation [19-22] of invading, foreign, biological material. The characterisation of hemocytes under natural, ambient conditions is essential to further understand cell-mediated responses of molluscs to environmental, anthropogenic and pathological stresses. Types and functions of molluscan hemocytes, however, have not been fully described. Until now, most knowledge of molluscan hemocytes has been from bivalve species [2,17,23,24], mainly because of their high economic value [25]. Hemocytes of gastropods have been investigated mainly in biomedically important snail species, such as Biomphalaria glabrata [26-31] and Lymnaea stagnalis [32-37]. B. glabrata and L. stagnalis are, respectively, intermediate hosts for the human parasitic blood fluke Schistosoma mansoni, responsible for schistosomiasis, a parasitic disease affecting roughly 200 million people throughout the world [38], and the avian Schistosoma parasite, which can accidentally infect humans [39]. Gastropod hemocyte characterisation was also reported in the abalone species Haliotis diversicolor [40,41], Haliotis asinina 
[42], Haliotis rufescens, Haliotis cracherodii [43,44] and Haliotis tuberculata [45-47] and in only a few other gastropods [48-51]. Classification of molluscan hemocytes commonly has been based upon morphological and biochemical features analysed by light and electron microscopy [1,40,48-52]. Flow cytometry also has been applied to molluscan hemocyte studies but, until now, mostly in bivalve species [53-61], with only very few studies of gastropods [36,37,46,47,62,63]. Although controversies still persist about molluscan hemocyte classification, two main classes are generally accepted: granulocytes, containing many intra-cytoplasmic granules, and agranulocytes, with no or fewer granules $[1,2,24,64]$. While granulocyte population may appear to be homogeneous, various agranulocyte subpopulations were reported, including different subtypes of hyalinocytes $[24,27,40,48,49,56,58,60]$ and juvenile or blast-like cells $[27,40,46,49,61,65-67]$. It is not clear currently whether such diversity in hemocyte subtypes represents distinct cell lineages, differences in differentiation and/or physiological state, or variations in methodology being applied. The disk abalone Haliotis discus discus and the spiny top shell Turbo cornutus are two representatives of the vetigastropods, a very ancient evolutionary lineage of marine gastropods. Both species are edible molluscs of high economic value in Asia. Worldwide stock abundance of abalones and top shells has been impacted by mass mortalities and large fluctuations [68]. Understanding the immune systems of these species is necessary to better assess the relative contributions of environmental factors, pathogenic infections and culture-related stresses in mortality outbreaks. In the present report, we applied light microscopy and flow cytometry to characterize the populations and immune-related activities of the circulating hemocytes of the disk abalone and the spiny top shell.

\section{Material and methods}

\subsection{Sampling schedule}

In March and April 2009, adult spiny top shells $(57.0-73.0 \mathrm{~mm}$ in shell height) and adult disk abalones (57.5 - $70.0 \mathrm{~mm}$ in shell length) were collected from southern waters of Cheju Island, Korea (3393' N 12693' E; Fig. 1). After arrival in the laboratory, shellfish were placed in tanks of seawater (salinity 30 ; temperature $15^{\circ} \mathrm{C}$ ) and kept for at lea st $24 \mathrm{~h}$ to acclimate and recover from rearing and transportation stresses.

\subsection{Hemolymph collection}

Using a syringe fitted with a 22-gauge needle, approximately $1.5-2.0 \mathrm{~mL}$ of hemolymph were collected. The needle was inserted between the operculum and the shell into the ring muscle of spiny top shells. Disk abalone hemolymph was withdrawn from the cephalic arterial sinus, accessed anteriorly at the angle between the foot and the head. Collected hemolymph was immediately transferred into micro tubes and kept on ice. Hemolymph from individuals was examined and was not pooled for subsequent microscopy and flow cytometric assays.

\subsection{Light microscopy}

Hemolymph cell monolayers (HCMs) were prepared by cytocentrifugation. Withdrawn hemolymph was fixed with an equal volume of $3 \%$ formalin prepared in filtered sterile seawater (FSSW) prior to being cyto-centrifuged. Cyto-centrifuged HCMs were then transferred into 100\% methanol prior to being stained with Hemacolor reagents (Merck). Air-dried, stained HCM slides were subsequently mounted and observed microscopically. Cell and nucleus diameters of hemocytes were measured, and cells from each population were counted using image-analysis software (ImageJ 1.410).

\subsection{Flow cytometry analysis}

\subsubsection{Hemocyte populations and concentration}

Concentration of hemocytes (Total Hemocyte Count, THC) and hemocyte cell-type populations were determined using SYBR Green I (Sigma-Aldrich), a membrane permeable, fluorescent dye that binds to double-stranded DNA. Fixed hemolymph (3\% formalin, v:v) was mixed with SYBR Green I solution (final dilution 10x) and incubated $30 \mathrm{~min}$ in the dark at room temperature before flow cytometric analysis (FACSCalibur; Becton Dickinson, San Diego, CA, USA). Hemocyte subtypes were discriminated based upon relative flow-cytometric morphological parameters, Forward Scatter (FSC) and Side Scatter (SSC). FSC and SSC commonly measure particle size and internal complexity, respectively. Internal complexity, also reported as granularity, depends upon various inner components of the cells including shape of the nucleus, amount and types of cytoplasmic granules, cytoplasmic inclusions and membrane roughness. Morphological parameters are expressed in arbitrary flow-cytometric units (A.U.) and THC is reported as the number of cells $\mathrm{mL}^{-1}$ of hemolymph. 


\subsubsection{Hemocyte viability}

Percentage of viable hemocytes was determined with the propidium iodide (PI; Sigma-Aldrich) exclusion method. Membranes of viable cells do not allow PI to penetrate; whereas, altered membranes are permeable to PI. Dead cells are characterized by loss of membrane integrity and are, therefore, stained by PI. Hemolymph was mixed with an equal volume of antiaggregant solution (AASH; $2.5 \% \mathrm{NaCl}$ and $1.5 \%$ EDTA in $0.1 \mathrm{M}$ phosphate buffer, $\mathrm{pH} 7.4 ;$ [69]) containing $\mathrm{PI}$ at the final concentration of $20 \mathrm{mg} \mathrm{mL}^{-1}$ and incubated for $10 \mathrm{~min}$ in the dark, prior to flow cytometric data acquisition. Hemocyte viability is expressed as the percentage of PI negative cells (i.e., cells with intact cytoplasmic membrane) and determined by the relative level of PI-related fluorescence (FL2 detector of the flow cytometer).

\subsubsection{Lysosome quantification}

The presence of lysosomes in hemocytes was determined using LysoTracker Red (Molecular Probes, Invitrogen), a membrane permeable, fluorescent red probe (emission maximum at $\sim 590 \mathrm{~nm}$ ) that accumulates within lysosomal compartments. Hemolymphwas diluted in AASH (v:v) containing LysoTracker Red (final dilution $1 \mathrm{mM}$ ). Mixed solutions were incubated $60 \mathrm{~min}$ in the dark, at room temperature. Tubes were then transferred and held on ice until flow cytometric analysis. Relative intracellular lysosomal quantity is expressed as the level of red fluorescence (FL3 detector of the flow cytometer) in arbitrary units (A.U.).

\subsubsection{Phagocytosis quantification}

Hemolymph samples were mixed with FSSW (v:v) in 24-well plates (Tissue Culture Testplate, SPL Lifesciences). Hemocytes were allowed to adhere for $20 \mathrm{~min}$ at room temperature (20-22 $\mathrm{C}$ ), and 60 $\mathrm{mL}$ of fluorescent beads $(2.0 \mathrm{~mm}$ in diameter; Working solution concentration at $2 \%$ in FSSW; Polysciences Inc) were then added to each well. Control wells received the phagocytosis inhibitor cytochalasin B (final concentration $10 \mathrm{mg} \mathrm{mL}^{-1}$; Sigma-Aldrich). After different times of incubation (10, $30,60,120$ and $180 \mathrm{~min})$, supernatants were discarded and trypsin $\left(2.5 \mathrm{mg} \mathrm{mL}^{-1}\right.$ in AASH, SigmaAldrich) was added to detach the adherent cells. Hemocytes were then centrifuged, resuspended in $3 \%$ formalin and held on ice until flow cytometric analysis. Association of hemocytes with fluorescent beads in control tubes (i.e., with cytochalasin B) was considered as attributable to adhering beads, not phagocytosis. A "Phagocytosis index" was then determined as the difference between the percentage of hemocytes associated with at least one bead in controls and samples. At each time and for each sample, the mean number of beads in phagocytic hemocytes (i.e., containing at least one bead) was also determined.

\subsubsection{Oxidative activity}

Determination of oxidative activity was performed at room temperature (20-22 $\mathrm{C})$ in 24-wells microplates, using 2'7'-dichlorofluorescein diacetate (DCFH-DA; Molecular Probes, Invitrogen), a membrane permeable, non-fluorescent probe. Inside hemocytes, the -DA radical is first hydrolyzed by esterase enzymes. Intracellular hydrogen peroxide (H2O2), as well as superoxide ion $\left(\mathrm{O}_{2}{ }^{-} ;[70,71]\right)$, then oxidizes DCFH to the fluorescent DCF molecule. Oxidation of DCFH can also be mediated by nitrite radicals $\left(\mathrm{NO}_{2}\right.$ or $\left.\mathrm{N}_{2} \mathrm{O}_{3}\right)$ [72] and various oxidase and peroxidase enzymes [73]. DCF green fluorescence, detected on the FL1 detector of the flow cytometer, is proportional to the total oxidative activity of hemocytes, including reactive oxygen species (ROS) and reactive nitrogen species (RNS). Oxidative activity of hemocytes was stimulated by the addition of phorbol 1,2-myristate 1,3-acetate (PMA, Sigma-Aldrich). PMA is a phorbol ester which can activate protein kinase C (PKC), involved in activation of NADPH oxidase (NOX) and nitric oxide synthase (NOS) molecules, responsible for the production of ROS and RNS, respectively. Briefly, diluted hemocyte suspensions (v:v in FSSW) were allowed to adhere for 20 min before adding DCFH-DA (final concentration $10 \mathrm{mM}$ ) and PMA (final concentration $10 \mathrm{mg} \mathrm{mL}^{-1}$ ). After 10, 30,60, 120 and $180 \mathrm{~min}$, hemocytes were detached with trypsin, as previously described. After centrifugation, hemocytes were fixed in $3 \%$ formalin and held on ice until flow cytometric analysis. Relative oxidative activity is expressed as the level of green fluorescence (FL1 detector of the flow cytometer) in arbitrary units (A.U.)

\subsubsection{Inhibitors of oxidative pathways}

Involvement of oxidative pathways in ROS and RNS production was investigated through the use of several inhibitors. L-NIO (L-N5- (1-iminoethyl)ornitine hydrochloride) is a modulator of RNS production through the inhibition of NOS activity. Apocynin (4'-Hydroxy-3'methoxyacetophenone) inhibits the NOX 
pathway, and fccp (carbonyl cyanide 4-(trifluoromethoxy)phenylhydrazone) acts as an uncoupler of mitochondrial oxidative phosphorylation.

Finally, DPI (Diphenyleneiodonium chloride) inhibits NOX and NOS complexes as well as mitochondrial complex I, the main site of ROS production in mitochondria. Determination of oxidative activity was done in 24-well microplates, as previously described. Inhibitors were mixed with hemocyte suspensions prior to adding DCFH-DA and PMA. All inhibitors were purchased from Sigma-Aldrich and used at a final concentration of $50 \mathrm{mM}$. Results are given as means of three replicates and expressed as percentages of control (i.e., without inhibitor).

\subsection{Statistical analysis}

One-way analysis of variance (ANOVA) and Tukey HSD test, when required, were carried out to compare the characteristics of hemocyte populations between disk abalone and spiny top shell. The percentage data were transformed as arc sine of the square root before ANOVA, but are presented in figures as untransformed percentage values. All results are expressed as mean $\pm 95 \%$ confidence interval $(\mathrm{Cl})$.

\section{Results}

\subsection{Morphological and cytometric identification of hemocyte populations}

\subsubsection{Light microscopy}

Two main hemocyte populations were distinguished in $\mathrm{H}$. discus discus hemolymph (Fig. 2A): blastlike cells and hyalinocytes. Blastlike cells accounted for less than $4 \%$ of circulating hemocytes (Table 1) and were small round cells with a very thin cytoplasmic layer surrounding the nucleus. Consequently, blast-like cells displayed a high nucleus $(\mathrm{N}) / \mathrm{cell}(\mathrm{C})$ size ratio $(\mathrm{N} / \mathrm{C} ; 0.82 \pm 0.01)$. Hyalinocytes were significantly (ANOVA, $p<0.01$ ) larger, round or ovoid cells $(9.39 \pm 0.16 \mathrm{~mm}$ ) with vacuolated cytoplasm. Hyalinocytes represented more than $96 \%$ of abalone hemocytes. In some individuals, hyalinocyte nuclei were bilobed and elongated; and hyalinocytes sometimes contained a unique, very large cytoplasmic vacuole (Fig. 2B). The hemolymph of the spiny top shells contained four major hemocyte populations (Fig. 3): blast-like cells, type I hyalinocytes, type II hyalinocytes and granulocytes. The small, round cells with very thin cytoplasmic layer accounted for about $4 \%$ of circulating hemocytes and were similar to those observed in the hemolymph of disk abalone; these cells were as also termed blast-like cells (Fig. 3C). Two subtypes were distinguishable amongst hyalinocytes and named as type I hyalinocytes and type II hyalinocytes. Type I hyalinocytes (Fig. 3D) were intermediate sized cells with intermediate N/C ratio $\left(0.59 \_0.01\right)$ and centric or slightly eccentric nucleus. Type I hyalinocytes accounted for about $55 \%$ of circulating hemocytes. Conversely, nucleus of type II hyalinocytes was clearly eccentric and their cytoplasm contained numerous small vacuoles (Fig. 3A, B, E). Type II hyalinocytes were larger than type I hyalinocytes with a smaller N/C ratio $(0.43$ \pm 0.01 ). Type II hyalinocytes represented about $38 \%$ of spiny top shell hemocytes. Numerous intracytoplasmic, acidophilic granules could be observed in granulocytes (Fig. 3F). Granulocytes were large cells $(15.16 \pm 1.19 \mathrm{~mm})$ morphologically similar to type II hyalinocytes, including eccentric nucleus, low N/C ratio $(0.41 \pm 0.02)$ and vacuolated cytoplasm. Cell size, nuclear diameter and N/C ratio of granulocytes and type II hyalinocytes were statistically (ANOVA) not different. Granulocytes were seldom observed in formalin-fixed cyto-centrifuged HCMs and accounted for approximately $3 \%$ of $T$. cornutus hemocytes.

\subsubsection{Flow cytometric analysis}

The viable hemocytes in $H$. discus discus and $T$. cornutus accounted for more than $99 \%$ of total cells. Mean total hemocyte count (THC) in disk abalone $\left(2.24 \times 10^{6}\right.$ cell $\left.\mathrm{mL}^{-1} ; \mathrm{n}=38\right)$ was significantly (ANOVA, $p<0.05)$ higher than in spiny top shell $\left(1.50 \times 10^{6}\right.$ cell $\left.^{-1} ; n=35\right)$. Flow cytometry allows for the discrimination of hemocyte populations by two morphological parameters, Forward Scatter (FSC) and Side Scatter (SSC) that are related to relative cell size and internal complexity. Two hemocyte populations were distinguishable in formalin-fixed abalone hemolymph (Fig. 4A): blast-like cells and hyalinocytes; whereas, three populations were observed in spiny top shell hemolymph (Fig. 4B): blast-like cells, hyalinocytes and granulocytes. Flow-cytometrically determined size and internal complexity values, as well as the relative percentage of each hemocyte population are reported in Table 2. In both species, small, agranular cells accounted for less than $10 \%$ of circulating hemocytes $(6.75 \pm 1.72 \%$ in the disk abalone and $8.94 \pm 3.16 \%$ in the spiny top shell) and were thought as blastlike cells. Hyalinocytes were larger (ANOVA, $p<0.01$ ), agranular cells representing more than $90 \%$ of circulating hemocytes in $\mathrm{H}$. discus discus and about $75 \%$ in $T$. cornutus. Granulocytes could only be 
observed in spiny top shell hemolymph and accounted for approximately $15 \%$ of all hemocytes. Granulocytes displayed statistically-similar (ANOVA) size as hyalinocytes but a higher (ANOVA, $p<$ 0.01 ) internal complexity. The presence of lysosomes in the hemocytes of $H$. discus discus and $T$. cornutus is shown in Fig. 5. The hemocytes of disk abalone displayed homogeneous contents in lysosomes (Fig. 5A); whereas, at least three subpopulations were distinguishable amongst spiny top shell hemocytes (Fig. 5B). LysoTracker ${ }^{\text {Low }}$ hemocytes were small, agranular cells accounting for about $10 \%$ of hemocytes (Fig. 5C1; Table 3). The hemocyte subpopulation displaying intermediate lysosomal content (LysoTracker ${ }^{\text {Med }}$ ) was composed of medium-sized cells representing about $20 \%$ of circulating hemocytes (Fig. 5C2; Table 3). Finally, hemocytes containing very high lysosomal amounts (LysoTracker ${ }^{\text {High }}$ ) accounted for about $70 \%$ of cells and were heterogeneous in terms of cell size and internal complexity (Fig. 5C3; Table 3).

\subsection{Flow cytometric characterisation of the immune-related activities of hemocytes}

\subsubsection{Phagocytosis}

Phagocytic activities of the hemocytes of disk abalone and spiny top shell were determined in two different ways: the phagocytosis index, determined as the percentage of cells that had engulfed at least one fluorescent latex bead (Fig. 6A), and the mean number of beads per phagocytic hemocyte (Fig. 6B). The development of phagocytosis index of the hemocytes of $H$. discus discus and $T$. cornutus was similar over the time (Fig. 6A), increasing linearly to approximately $22 \%$ of phagocytic cells at $180 \mathrm{~min}$. Conversely, dissimilarities were observed between species concerning the average quantity of engulfed beads (Fig. 6B). After 120 and 180 min, the mean number of engulfed beads was higher (ANOVA, $p<0.01$ ) in disk abalone than in spiny top shell hemocytes. At the end of the experiment, the mean number of beads engulfed was $2.81 \pm 0.21$ in $H$. discus discus and $2.16 \pm 0.16$ in $T$. cornutus hemocytes.

\subsubsection{Oxidative activity}

Oxidative activity was successfully detected in the hemocytes of the disk abalone (Fig. 7A) and the spiny top shell (Fig. 7B). Oxidative activity in blast-like cells from both species was extremely low compared to other hemocyte types. Consequently, blast-like cells were excluded from the measurements of oxidative activity. Basal (i.e., non-stimulated) oxidative activity did not change in the course of experiments and was similar in $H$. discus discus and T. cornutus hemocytes (Fig. 7A and B). Conversely, the effects of PMA stimulation were dissimilar between disk abalone (Fig. 7A and $\mathrm{C}$ ) and spiny top shell hemocytes (Fig. 7B and C). PMA-stimulated oxidative activity of abalone hemocytes did not markedly increase until $60 \mathrm{~min}$ (about $120 \%$ of non-stimulated condition between 10 and $60 \mathrm{~min}$ ). After $60 \mathrm{~min}$, oxidative activity of PMA-stimulated abalone hemocytes increased to reach approximately 90 A.U. at $3 \mathrm{~h}$ (about $265 \%$ of the non-stimulated condition; Fig. 7A and C). In contrast, PMA stimulation of top shell hemocytes quickly resulted in an increased oxidative activity $(225 \%$ and $250 \%$ of the nonstimulated condition as soon as 10 and $30 \mathrm{~min}$, respectively; Fig. 7C). PMA-induced oxidative activity then remained rather stable from 30 to $180 \mathrm{~min}$ (approximately 70 A.U. and $225 \%$ of the non-stimulated condition; Fig. 7B and C).

\subsubsection{Oxidative pathways}

Pathways potentially involved in the oxidative activity of the hemocytes of disk abalone and spiny top shell were investigated using inhibitors. Effects of inhibitors, measured with or without PMA stimulation, were expressed as the percentage of control (i.e., without inhibitor) and presented in Fig. 8.

\subsubsection{L-NIO}

L-NIO is an inhibitor of nitric oxide synthase (NOS) which is involved in reactive nitrogen species (RNS) production. L-NIO induced no noticeable effect under any experimental conditions.

\subsubsection{Apocynin}

Apocynin inhibits NADPH oxidase (NOX) production of reactive oxygen species (ROS). Apocynin had no effect on unstimulated abalone and top shell hemocytes (Fig. 8A and C). Contrastingly, apocynin significantly (ANOVA, $p<0.05$ ) inhibited up to $30 \%$ of oxidative activity in PMA-stimulated hemocytes from disk abalone and spiny top shell (Fig. 8B and D).

\subsubsection{Fccp}

Oxidative activity of unstimulated and PMA-stimulated hemocytes from $H$. discus discus and $T$. cornutus was significantly (ANOVA, $p<0.05)$ inhibited $(40-50 \%$ inhibition) when incubated with fccp, a mitochondrion-uncoupling agent. An exception was observed with unstimulated hemocytes of the 
disk abalone, in which oxidative activity increased of about 30\% after 180 min treatment with fccp (Fig. $8 \mathrm{~A})$.

\subsubsection{DPI}

$\mathrm{DPI}$ is an inhibitor of NOS, NOX and the mitochondrial oxidative pathway. DPI inhibited from 30 to $60 \%$ of oxidative activity in unstimulated hemocytes from disk abalone and spiny top shell (Fig. $8 \mathrm{~A}$ and C), and from 50 to $70 \%$ of oxidative activity in PMA-stimulated hemocytes from both species (Fig. 8B and D).

\section{Discussion}

The disk abalone and the spiny top shell are two edible gastropod species of high economic importance in Asia. Currently, very few studies have been reported about ecology, biology and immunity of both species [68,74-76]. Characterisation of the immune systems of these species is necessary to further assess responses to environmental, anthropogenic and pathological stresses. Indeed, mass mortality outbreaks have occurred worldwide, resulting in economic and ecological losses $[47,68]$. Viral infections were reported in disk abalone and spiny top shell [77-79], but currently the effects of resulting diseases and sensitivity to infections depending upon environmental factors such as seasonality, global warming or pollution have not been determined. In the present report we used light microscopy and flow cytometry to investigate the populations and immune-related activities of hemocytes in the disk abalone $\mathrm{H}$. discus discus and the spiny top shell $T$. cornutus. Hemocyte populations and activities vary greatly with environmental conditions as well as individual physiological status [47,80-84]. One should keep in mind, therefore, that descriptions of disk abalone and spiny top shell hemocyte parameters might depend on rearing site and seasonality. In the present study, individuals from both species were simultaneously supplied from the same location. Inter-species differences might be more apparent than intra-species variations. The hemopoiesis of molluscs has not yet been fully understood. Two major theories have been proposed to explain differentiation of hemocytes. Based upon the observation of granules in some juvenile cells, Cheng [2] and Auffret [64] suggested that hyalinocytes and granulocytes might differentiate from two distinct cell precursors. Granuloblasts (i.e., juvenile cells containing granules), however, have since been extremely rarely observed and, in the absence of this kind of cell, Hine [24] suggested that one blast type might give rise to hyalinocytes that would further mature to become granulocytes. Results of the present report tend to support Hine's hypothesis. Indeed, granules were never observed in blastlike cells from disk abalone and spiny top shell. Furthermore, hemocyte populations of $T$. cornutus microscopically appeared as a gradient of differentiation stages (Fig. 4C-F) with a continuous decrease of N/C ratio (Table 1). Blast-like cells might then differentiate into type I hyalinocytes which still contain central or slightly eccentric nucleus; whereas, type II hyalinocytes display a fully eccentric nucleus and vacuolated cytoplasm. Finally, granulocytes might represent mature hemocytes with numerous intracytoplasmic vacuoles and granules. Similar differentiation was suggested in the common periwinkle Littorina littorea [49] and in the snails Pila globosa and Indoplanorbis exustus [51]. Further analyses of gene expression, DNA content and membrane molecular expression, however, will have to be performed to confirm gastropod hemopoiesis. In the disk abalone, neither flow cytometry analysis nor light microscopic observation of formalin-fixed HCMs allowed discrimination of granulocytes. In the European abalone $H$. tuberculata, Travers et al. [46] also pointed out the incapacity to discriminate between hyalinocytes and granulocytes through flow cytometric analysis. Conversely, granulocytes were reported under light microscopic and flow cytometric analyses in the spiny top shell. No granular hemocytes were described in some gastropod species, including the abalone $H$. diversicolor [40], the common periwinkle L. littorea [49], the sea hare Aplysia californica and the giant keyhole limpet Megathura crenulata [50]. In contrast, granulocytes were reported in some other species including the terrestrial snail Helix aspersa maxima [48], the abalone $H$. asinina [42], and the freshwater snails B. glabrata [27], Biomphalaria tenagophila [65], P. globosa and I. exustus [51]. The term "granulocyte", as defined in bivalves, appears difficult to apply in gastropods. Indeed, although the present study and some previous authors reported a subtype of hemocytes as "granulocytes", these cells did not exhibit similar, characteristic granular features as described among bivalves $[2,24,54,58,60]$. Granulocyte terminology might thus need to be reconsidered in gastropods. A classification scheme based upon cellular activities might represent an alternative. In this way, flow cytometry allows single cell level analysis and might help to discriminate differential activities of hemocyte subtypes. The involvement of hemocytes in mollusc cellular immune response mainly relies on their capacity to engulf and subsequently degrade foreign material through phagocytosis $[17,18,85-87]$. In the present study, hemocytes from $H$. discus discus and $T$. cornutus displayed 
phagocytic activity stimulated by latex beads. Although granulocytes were reported as the main phagocytic hemocyte type in some marine bivalves [60,61,88-90], it was not possible to specifically determine phagocytic activity of spiny top shell granulocytes and hyalinocytes because ingestion of latex beads caused cells to change size and internal complexity (data not shown). In the present study, development of the phagocytosis index was similar in the disk abalone and the spiny top shell. Contrastingly, at the end of the experiment, the mean number of engulfed beads was higher in $H$. discus discus than in $T$. cornutus. Although phagocytosis index was similar, disk abalone hemocytes actually displayed higher total phagocytic activity than spiny top shell hemocytes. In further studies, it might then be interesting to assess if such differences in global phagocytic capacity could be related to variation in microbicidal activities between both species. Lysosomes are intra-cytoplasmic, acidic organelles involved in the intracellular degradation of engulfed foreign material through the acidification of the phagocytic vacuoles and the release of lysosomal enzymes (for review on lysosomes see [91]). Detection of lysosomes in the hemocytes of gastropods was commonly accomplished using Neutral Red stain and microscopic observation [41,46,50,92]. To our knowledge, this is the first time lysosomal quantity was determined by flow cytometry in gastropod hemocytes. One lysosomal-defined hemocyte population was observed in the disk abalone. Blast-like cells surprisingly displayed similar lysosomal quantity as hyalinocytes; whereas, blast-like cells are thought to lack functions such as phagocytosis. The LysoTracker probe actually accumulates in intracytoplasmic acidic compartments which are mainly lysosomes. Travers et al. [46], however, reported that in the European abalone $H$. tuberculata, the cytoplasm of blast-like cells was highly acidic. It is not clear, therefore, whether LysoTracker staining of the blast-like cells in the disk abalone relies on presence of lysosomes or results from the highly acidic cytoplasm and might be considered as an artifact. In contrast, three subtypes could be distinguished among spiny top shell hemocytes. A differential content of lysosomes might be related to functional differences but could also vary with differentiation stage. Further flow cytometric sorting of lysosomal defined hemocyte subtypes of $T$. cornutus could help assess if such subsets are related to microscopically-observed hyalinocytes type I, II and granulocytes. The involvement of oxidative activity, including the production of reactive oxygen species (ROS) and reactive nitrogen species (RNS), in immune response was first described in the polymorphonuclear leukocytes of vertebrates [93,94]. Oxidative activity has been detected subsequently in molluscs, including gastropod species [29-31,33-35,41,44,45,47,50,95]. The activation of oxidative activity has been studied using various stimulants among which killed yeast cells and phorbol myristate acetate (PMA) are the most reported. Stimulation by killed yeast cells relies on the phagocytic activities of the hemocytes. Conversely, PMA chemically activates ROS and RNS production through the phosphorylation of protein kinase $C(P K C)$ and the subsequent activation of NADPH oxidase (NOX) and nitric oxide synthase (NOS) complexes [96-99]. To avoid a possible bias from altered phagocytic activities, PMA stimulation was selected. The present results confirm the capacity of PMA to stimulate oxidative activity of gastropod hemocytes, within a similar range of values as previously reported in the common periwinkle L. littorea [95] and the freshwater snail B. glabrata [31]. The kinetics of stimulated oxidative activities were dissimilar between the disk abalone and the spiny top shell. Oxidative activity quickly increased in $T$. cornutus hemocytes, reaching maximal value between 10 and $30 \mathrm{~min}$; whereas, a one-hour latent phase was observed in $\mathrm{H}$. discus discus hemocytes followed by a regular increase of oxidative activity until the end of the experiment. Different patterns of stimulated oxidative activity might be species specific, as previously reported in bivalves. Indeed, the increase in oxidative activity happened between 15 and $40 \mathrm{~min}$ for the oysters Crassostrea gigas [97,100], between 30 and 60 min in Crassostrea virginica [59] and around 70 min in Mercenaria mercenaria [101]. Such differences might result from differential capacities of disk abalone and spiny top shell to regulate oxidative activity. The analysis of the expression and activity of antioxidant enzymes such as catalase and superoxide dismutase might help elucidate the reported dissimilarities. To investigate the pathways potentially involved in the oxidative activity of $\mathrm{H}$. discus discus and T. cornutus hemocytes, we used chemical inhibitors. In the present study, RNS production seemed not predominant in the hemocytes of disk abalone and spiny top shell, with or without PMA stimulation, although NOS activity was detected in the freshwater snail Viviparus ater [102] and RNS production reported from L. stagnalis [35]. Interestingly, apocynin, an inhibitor of NOX isoforms $[103,104]$ only inhibited oxidative activity during PMA stimulation. NOX-dependant ROS production was then stimulated by PMA but seemed not constitutively predominant in the hemocytes of disk abalone and spiny top shell. This is a new finding, as basal and stimulated ROS production was commonly attributed to NOX complexes. Such statements were mostly based on the inhibition of oxidative activity by DPI, which was commonly suggested as an inhibitor of NOX-dependant ROS production, and not mitochondrial oxidative activity $[30,101,105]$. Actually, DPI inhibits NOX and NOS complexes as well as mitochondrial complex I, one of the two main sites of ROS production in 
mitochondria [103]. Our experiments suggested that oxidative activity in disk abalone and spiny top shell hemocytes mostly originates from mitochondria. Indeed, incubation with fccp, uncoupler of mitochondrial oxidative phosphorylation, strongly inhibited oxidative activity of hemocytes. The percentage of inhibition was in the same range of values than reported in isolated rat mitochondria [106] and in Jurkat cells, a human T lymphocyte cell line [107]. The increase in oxidative activity observed after $3 \mathrm{~h}$ in non-stimulated hemocytes of disk abalone incubated with fccp was also reported in Jurkat cells by Aronis et al. [107] and hypothesized as "owing to adaptation as a result of compensation mechanism of the cell". In vertebrates, phagocytosis and PMA stimulation induce an "oxidative burst", characterized by a very intense, but brief reaction [97] which does not match with the phenomenon observed in gastropods. Indeed, the oxidative activity peak in hemocytes can be delayed and the increase only between 2 and 10 [30,31,33,35,41,95]. Although further studies will be needed, we suggest that such differences could be explained, at least in part, by lower NOX-dependant ROS production in gastropods than in vertebrates and a predominant mitochondrial oxidative activity. The present study was the first to characterize the cellular component of the immune system of the disk abalone $H$. discus discus and the spiny top shell $T$. cornutus. Although both species belong to the vetigastropods, differences were observed in hemocyte populations and immune-related activities. The hemocytes of the disk abalone were composed of two populations, blast-like cells and hyalinocytes. In contrast, the hemocytes of the spiny top shell belonged to four morphologically defined populations: blast-like cells, hyalinocytes type I and II, and granulocytes. Our results reported differences between the two species concerning the intracellular amount of lysosomes, the phagocytic activities and the oxidative activities. Further investigations will have to be performed to determine if such differences rely on true functional dissimilarities. It might then be important to assess the capacity of the hemocytes of both species to kill various pathogens, to depurate organic and inorganic pollutants, as well as their response to environmental or mechanical stresses.

Acknowledgments

The authors thank the staff of the Shellfish Aquaculture and Research Laboratory, Jeju National University. This study was supported by research fund from the Korean Ministry of Land, Transport and Maritime Affairs (PM55020: Oil Spill Environmental Impact Assessment and Environmental Restoration).We appreciate the support. Sincere thanks are due to Dr. Gary H. Wikfors for the English corrections.

\section{References}

[1] Cheng TC. Functional morphology and biochemistry of molluscan phagocytes. Ann NY Acad Sci 1975;266:343-79.

[2] Cheng TC. Bivalves. In: Ratcliffe NA, Rowly AF, editors. Invertebrate blood cells. London, UK: Academic Press; 1981. p. 233-300.

[3] Sminia T. Gastropods. In: Ratcliffe NA, Rowly AF, editors. Invertebrate blood cells. London, UK: Academic Press; 1981. p. 191-232.

[4] Pollero RJ, Huca G, Brenuer RR. Role of hemocytes and plasma on lipid transport in freshwater mollusk. Diplodon delodontus. Comp Biochem Physiol 1985;82A:339-43.

[5] Cheng TC. Hemocytes: forms and functions. In: Kennedy VS, Newell RIE, Eble AF, editors. The eastern oyster Crassostrea virginica. College Park, MD, USA: Maryland Sea Grant Book; 1996. p. 299-333.

[6] Beninger PG, Le Pennec G, Le Pennec M. Demonstration of nutrient pathway from the digestive system to oocytes in the gonad intestinal loop of the scallop Pecten maximus L. Biol Bull 2003;205:83-92.

[7] Armstrong DA, Armstrong JL, Krassner SM, Pauley GB. Experimental wound repair in the black abalone. Haliotis cracherodii. J Invertebr Pathol 1971;17:216-27.

[8] Sparks AK, Morado JF. Inflammation and wound repair in bivalve molluscs. In: Fisher WS, editor. Disease processes in marine bivalve molluscs, vol. 18. Bethesda, MD, USA: American Fisheries Society; 1988. p. 139-52.

[9] Mount AS, Wheeler AP, Paradkar RP, Snider D. Hemocyte-mediated shell mineralization in the eastern oyster. Science 2004;304:297-300.

[10] Matozzo V, Ballarin L, Pampanin DM, Marin MG. Effects of copper and cadmium exposure on functional responses of hemocytes in the clam, Tapes philippinarum. Arch Environ Contam Toxicol 2001;41:163-70. 
[11] Fisher WS. Antimicrobial activity of copper and zinc accumulated in eastern oyster amebocytes. J Shellfish Res 2004;23:321-51.

[12] Fisher WS. Relationship of amebocytes and terrestrial elements to adult shell deposition in eastern oysters. J Shellfish Res 2004;23:353-67.

[13] Tripp MR. The fate of foreign materials experimentally introduced into the snail Australorbis glabratus. J Parasitol 1961;47:745-51.

[14] Bayne CJ. Molluscan internal defence mechanism: the fate of $\mathrm{C} 14$ labelled bacteria in the land snail Helix pomatia (L.). J Comp Physiol 1973;86:17-25.

[15] Van der Knaap WPW, Sminia T, Kroese FGM, Dikkeboom R. Elimination of bacteria from the circulation of the pond snail Lymnaea stagnalis. Dev Comp Immunol 1981;5:21-32.

[16] Cheng TC. Cellular defense mechanisms in oysters. In: Fingerman N, NagabhushanamR, editors. Recent advances in marine biotechnology.Immunobiology and pathology. Enfield, $\mathrm{NH}$, USA: Science Publishers; 2000. p. 43-83.

[17] Chu FLE. Defense mechanisms of marine bivalves. In: Fingerman N, NagabhushanamR, editors. Recent advances in marine biotechnology. Immunobiology and pathology. Enfield, NH, USA: Science Publishers; 2000. p. 1-42.

[18] Canesi L, Gallo G, Gavioloi M, Pruzzo C. Bacteria-hemocyte interactions and phagocytosis in marine bivalves. Microsc Res Tech 2002;57:469-76.

[19] Harris KR. The fine structure of encapsulation in Biomphalaria glabrata. Ann NY Acad Sci 1975;266:446-63.

[20] Krupa PL, Lewis LM, Vecchio PD. Schistosoma haematobium in Bulinus guernei: electron microscopy of hemocyte-sporocyst Interactions. J Invert Pathol 1977;30:35-45.

[21] Chagot D, Comps M, Boulo V, Ruano F, Grizel H. Histological study of a cellular reaction in Ruditapes decussatus infected by a protozoan. Aquaculture 1987;67:260-1.

[22] Montes JF, Merce` D, Garcia-Valero J. Cellular defense mechanism of the clam Tapes semidecussatus against infection by the protozoan Perkinsus sp. Cell Tissue Res 1995;279:529-38.

[23] Chu FLE. Humoral defense factors in marine bivalves. Am Fish Soc Spec Publ 1988;18:178-88.

[24] Hine PM. The inter-relationships of bivalve haemocytes. Fish Shellfish Immunol 1999;9:367-85.

[25] Gosling E. Bivalve molluscs. Biology, ecology and culture. Oxford, UK: Blackwell Publishing; 2002.

[26] Yoshino TP, Granath Jr WO. Identification of antigenically distinct hemocyte subpopulations in Biomphalaria glabrata (Gastropoda) using monoclonal antibodies to surface membrane markers. Cell Tissue Res 1983;232:553-64.

[27] Matricon-Gondran M, Letocart M. Internal defenses of the snail Biomphalaria glabrata: I. Characterization of hemocytes and fixed phagocytes. J Invertebr Pathol 1999;74:224-34.

[28] Matricon-Gondran M, Letocart M. Internal defenses of the snail Biomphalaria glabrata. II. In vivo responses of hemocytes and fixed phagocytes to injected foreign materials. $\mathrm{J}$ Invertebr Pathol 1999;74:235-47.

[29] Hahn UK, Bender RC, Bayne CJ. Production of reactive oxygen species by hemocytes of Biomphalaria glabrata: carbohydrate-specific stimulation. Dev Comp Immunol 2000;24:531-41.

[30] Bender RC, Broderick EJ, Goodall CP, Bayne CJ. Respiratory burst of Biomphalaria glabrata hemocytes: Schistosoma mansoni-resistant snails produce more extracellular $\mathrm{H} 2 \mathrm{O} 2$ than susceptible snails. J Parasitol 2005;91:275-9.

[31] Humphries JE, Yoshino TP. Regulation of hydrogen peroxide release in circulating hemocytes of the planorbid snail Biomphalaria glabrata. Dev Comp Immunol 2008;32:554-62.

[32] Dikkeboom R, van der Knapp WPW, Maaskant JJ, de Jonge AJR. Different subpopulations of haemocytes in juvenile, adult and Trichobilharzia infected Lymnaea stagnalis: a characterisation using monoclonal antibodies. Z Parasitenkd Parasitol Res 1985;71:815-9.

[33] Zelck UE, Janje B, Schneider O. Superoxide dismutase expression and $\mathrm{H} 2 \mathrm{O} 2$ production by hemocytes of the trematode intermediate host Lymnaea stagnalis (Gastropoda). Dev Comp Immunol 2005;29:305-14.

[34] Lacchini AH, Davies AJ, Mackintosh D, Walker AJ. B-1, 3-glucan modulates PKC signalling in Lymnaea stagnalis defence cells: a role for $\mathrm{PKC}$ in $\mathrm{H} 2 \mathrm{O} 2$ production and downstream ERK activation. J Exp Biol 2006;209:4829-40. 
[35] Wright B, Lacchini AH, Davies AJ, Walker AJ. Regulation of nitric oxide production in Lymnaea stagnalis defence cells: a role for protein kinase $C$ and extracellular signal-regulated kinase signalling pathways. Biol Cell 2006;98:265-78.

[36] Russo J, Madec L. Haemocyte apoptosis as a general cellular immune response of Lymnaea stagnalis (Gastropoda, Pulmonata) to a toxican. Cell Tissue Res 2007;328:431-41.

[37] Russo J, Madec L, Brehe' lin M. Effect of a toxicant on phagocytosis pathways in the freshwater snail Lymnaea stagnalis. Cell Tissue Res 2008;333:147-58.

[38] Bayne CJ. Successful parasitism of vector snail Biomphalaria glabrata by the human blood fluke (trematode) Schistosoma mansoni: a 2009 assessment. Mol Biochem Parasitol 2009;165:818.

[39] Odom R, James W, Berger T. Andrews' diseases of the skin: clinical dermatology. 9th ed. Philadelphia: WB Saunders Company; 2000.

[40] Chen JH, Yang HY, Peng SW, Chen YJ, Tsai KY. Characterization of abalone (Haliotis diversicolor) hemocytes in vitro. Biol Bull 1996;31:31-8.

[41] Gopalakrishnan S, Thilagam H, Huang WB, Wang KJ. Immunomodulation in the marine gastropod Haliotis diversicolor exposed to benzo(a)pyrene. Chemosphere 2009;75:389-97.

[42] Sahaphong S, Linthong V,Wanichanon C, Riengrojpitak S, Kangwanrangsan N, Viyanant V, et al. Morphofunctional study of the hemocytes of Haliotis asinina. J Shellfish Res 2001;20:711-6.

[43] Martello LB, Friedman CS, Tjeedema RS. Combined effects of pentachlorophenol and salinity stress on phagocytic and chemotactic function in two species of abalone. Aquat Toxicol 2000;49:213-25.

[44] Martello LB, Tjeerdema RS. Combined effects of pentachorophenol and salinity stress on chemiluminescence activity in two species of abalone. Aquat Toxicol 2001;51:351-62.

[45] Malham SK, Lacoste A, Ge' le' bart F, Cueff A, Poulet SA. Evidence for a direct link between stress and immunity in the mollusk. Haliotis tuberculata. J Exp Zool 2003;295A:136-44.

[46] Travers MA, da Silva MP, Le Goı"c N, Marie D, Donval A, Huchette S, et al. Morphologic, cytometric and functional characterisation of abalone (Haliotis tuberculata) haemocytes. Fish Shellfish Immunol 2008;24:400-11.

[47] Travers MA, Le GoI"c N, Huchette S, Koken M, Paillard C. Summer immune depression associated with increased susceptibility of the European abalone, Haliotis tuberculata to Vibrio harveyi infection. Fish Shellfish Immunol 2008;25:800-8.

[48] Adamowicz A, Bolaczek M. Blood cells morphology of the snail Helix aspersa maxima (Helicidae). Zool Pol 2003;48:93-101.

[49] Gorbushin AM, lakovleva NV. Haemogram of Littorina littorea. J Mar Biol Assoc UK 2006;86:1175-81.

[50] Martin GG, Oakes CT, Tousignant HR, Crabtree H, Yamakawa R. Structure and function of haemocytes in two marine gastropods, Megathura crenulata and Aplysia californica. J Mollus Stud 2007;73:355-65.

[51] Mahilini HM, Rajendran A. Categorization of hemocytes of three gastropod species Trachea vittata (Muller), Pila globosa (Swainson) and Indoplanorbis exustus (Dehays). J Invertebr Pathol 2008;97:20-6.

[52] Adema CM, Harris RA, van Deutekom-Mulder EC. A comparative study of hemocytes from six different snails: morphology and functional aspects. J Invertebr Pathol 1992;59:24-32.

[53] Ford SE, Ashton-Alcox KA, Kanaley SA. Comparative cytometric and microscopic analyses of oyster haemocytes. J Invertebr Pathol 1994;64:114-22.

[54] Ashton-Alcox KA, Ford SE. Variability in molluscan hemocytes: a flow cytometric study. Tissue Cell 1998;30:195-204.

[55] Renault T, Xue QG, Chilmonczyk S. Flow cytometric analysis of European flat oyster, Ostrea edulis, haemocytes using a monoclonal antibody specific for granulocytes. Fish Shellfish Immunol 2001;11:269-74.

[56] Xue QG, Renault T, Chilmonczyk S. Flow cytometric assessment of haemocyte sub-populations in the European flat oyster, Ostrea edulis, haemolymph. Fish Shellfish Immunol 2001;11:55767. 
[57] Delaporte M, Soudant P, Moal J, Lambert C, Que' re' C, Miner P, et al. Effect of mono-specific algal diet on immune functions in two bivalve species - Crassostrea gigas and Ruditapes philippinarum. J Exp Biol 2003;206:3053-64.

[58] $\mathrm{He}^{\prime}$ garet $\mathrm{H}$, Wikfors $\mathrm{GH}$, Soudant P. Flow-cytometric analysis of haemocytes from eastern oysters, Crassostrea virginica, subjected to a sudden temperature elevation: I. Haemocyte types and morphology. J Exp Mar Biol Ecol 2003;293:237-48.

[59] $\mathrm{He}^{\prime}$ garet $\mathrm{H}$, Wikfors $\mathrm{GH}$, Soudant P. Flow cytometric analysis of haemocytes from eastern oysters, Crassostrea virginica, subjected to a sudden temperature elevation: II. Haemocyte functions: aggregation, viability, phagocytosis, and respiratory burst. J Exp Mar Biol Ecol 2003;293:249-65.

[60] Goedken M, DeGuise S. Flow cytometry as a tool to quantify oyster defense mechanisms. Fish Shellfish Immunol 2004;16:539-52.

[61] Donaghy L, Kim BK, Hong HK, Park HS, Choi KS. Flow cytometry studies on the populations and immune parameters of the hemocytes of the Suminoe oyster, Crassostrea ariakensis. Fish Shellfish Immunol 2009;27:296-301.

[62] Russo J, Lagadic L. Effects of environmental concentrations of atrazine on hemocyte density and phagocytic activity in the pond snail Lymnaea stagnalis (Gastropoda, Pulmonata). Environ Poll 2004;127:303-11.

[63] Cossarizza A, Pinti M, Troiano L, Cooper E. Flow cytometry as a tool for analyzing invertebrate cells. Invertebr Surv J 2005;2:32-40.

[64] Auffret M. Bivalve hemocyte morphology. Am Fish Soc Spec Publ 1988;18:169-77.

[65] Barraco MA, Steil AA, Gargioni R. Morphological characterization of the hemocytes of the pulmonate snail Biomphalaria tenagophila. Mem Inst Osw Cruz 1993;88:73-83.

[66] Cima F, Matozzo V, Marin MG, Ballarin L. Haemocytes of the clam Tapes philippinarum (Adams \& Reeve, 1850): morphofunctional characterisation. Fish Shellfish Immunol 2000;10:677-93.

[67] Aladaileh S, Nair SV, Birch D, Raftos DA. Sydney rock oyster (Saccostrea glomerata) hemocytes: morphology and function. J Invertebr Pathol 2007;96:48-63.

[68] Hayakawa J, Yamakawa T, Aoki I. Long-term fluctuation in the abundance of abalone and top shell in Japan and factors affecting those fluctuations. Bull Jpn Soc Fish Oceanogr 2007;71:96-105 [in Japanese with English abstract].

[69] Auffret M, Oubella R. Cytological and cytometric analysis of bivalves mollusc hemocytes. In: Stolen JS, Fletcher TC, Smith SA, Zelikoff JT, Kaattari SL, Anderson RS, So"derha" II K, Weeks-Perkins BA, editors. Techniques in fish immunology. Fair Haven: SOS Publications; 1995. p. 55-64.

[70] Rao KM, Padmanabhan J, Kilby DL, Cohen HJ, Currie MS, Weinberg JB. Flow cytometric analysis of nitric oxide production in human neutrophils using dichlorofluorescein diacetate in the presence of a calmodulin inhibitor. J Leukoc Biol 1992;51:496-500.

[71] Curtin JF, Donovan M, Cotter TG. Regulation and measurement of oxidative stress in apoptosis. J Immunol Methods 2002;265:49-72.

[72] Wardman P. Fluorescent and luminescent probes for measurement of oxidative and nitrosative species in cells and tissues: progress, pitfalls, and prospects. Free Radic Biol Med 2007;43:995-1022.

[73] Gomes A, Fernandes E, Lima J. Fluorescence probes used for detection of reactive oxygen species. J Biochem Biophys Methods 2005;65:45-80.

[74] Hayakawa J, Kawamura T, Ohashi S, Horii T, Watanabe Y. Habitat selection of Japanese top shell (Turbo cornutus) on articulated coralline algae; combination of preferences in settlement and post-settlement stage. J Exp Mar Biol Ecol 2008;363:118-23.

[75] De Zoysa M, Jung S, Lee J. First molluscan TNF-a homologue of the TNF superfamily in disk abalone: molecular characterization and expression analysis. Fish Shellfish Immunol 2009;26:625-31.

[76] Nikapitiya C, De Zoysa M, Lee J. Molecular characterization and gene expression analysis of a pattern recognition protein from disk abalone, Haliotis discus discus. Fish Shellfish Immunol 2008;25:638-47.

[77] Li X, Wang B, Liu S, Xu J. The infection to a few kinds of shellfish inshore by a kind of virus. J Dalian Fish Univ 2000;15:86-91 [in Chinese with English abstract]. 
[78] Zhengli S, Handlinger J. Abalone viral mortality - disease card. Bangkok, Thailand: NACA, http://library.enaca.org/Health/DiseaseLibrary/Abalone- Disease.pdf; 2004.

[79] Chang PH, Kuo ST, Lai SH, Yang HS, Ting YY, Hsu CL, et al. Herpes-like virus infection causing mortality of cultured abalone Haliotis diversicolor supertaxa in Taiwan. Dis Aquat Org 2005;65:23-7.

[80] Soudant P, Paillard C, Choquet G, Lambert C, Reid HI, Marhic A, et al. Impact of season and rearing site on the physiological and immunological parameters of the manila clam Venerupis (1/4 Tapes, 1/4 Ruditapes) philippinarum. Aquaculture 2004;229:401-18.

[81] Delaporte M, Soudant P, Lambert C, Jegaden M, Moal J, Pouvreau S, et al. Characterisation of physiological and immunological differences between Pacific oysters (Crassostrea gigas) genetically selected for high or low survival to summer mortalities and fed different rations under controlled conditions. J Exp Mar Biol Ecol 2007;353:45-57.

[82] Lambert C, Soudant P, De'gremont L, Delaporte M, Moal J, Boudry P, et al. Hemocyte characteristics in families of oysters, Crassostrea gigas, selected for differential survival during summer and reared in three sites. Aquaculture 2007;270:276-88.

[83] da Silva MP, Comesaña P, Fuentes J, Villalba A. Variability of haemocyte and haemolymph parameters in European flat oyster Ostrea edulis families obtained from brood stocks of different geographical origins and relation with infection by the protozoan Bonamia ostreae. Fish Shellfish Immunol 2008;24:551-63.

[84] Flye-Sainte-Marie J, Soudant P, Lambert C, Le Gol"c N, Goncalvez M, Travers MA, et al. Variability of the hemocyte parameters of Ruditapes philippinarum in the field during an annual cycle. J Exp Mar Biol Ecol 2009;377:1-11.

[85] Feng SY. Cellular defense mechanisms of oysters and mussels. Am Fish Soc Spec Publ 1988;18:153-68.

[86] Tiscar PG, Mosca F. Defense mechanisms in farmed marine molluscs. Vet Res Comm 2004;28S1:57-62.

[87] Hooper C, Day R, Slocombe R, Handlinger J, Benkendorff K. Stress and immune responses in abalone: limitations in current knowledge and investigative methods based on other models. Fish Shellfish Immunol 2007;22:363-79.

[88] Tripp MR. Phagocytosis by hemocytes of the hard clam, Mercenaria mercenaria. J Invertebr Pathol 1992;59:222-7.

[89] Lo' pez C, Carballal MJ, Azevedo C, Villalba A. Differential phagocytic ability of the circulating haemocyte types of the carpet shell clam Ruditapes decussatus (Mollusca: Bivalvia). Dis Aquat Org 1997;30:209-15.

[90] Bettencourt R, Dando P, Collins P, Costa V, Allam B, Serra o Santos R. Innate immunity in the deep sea hydrothermal vent mussel Bathymodiolus azoricus. Comp Biochem Physiol 2009;152A:278-89.

[91] Luzio JP, Pryor PR, Bright NA. Lysosomes: fusion and function. Nat Rev Mol Cell Biol 2007;8:622-32.

[92] Wang T, Li X, Bott K, Song L, Clarke S, Zhao W. Effects of water temperature on the lysosomal membrane stability in hemocytes of blacklip abalone, Haliotis rubra (Leach). J Shellfish Res 2006;25:935-40.

[93] Babior BM, Kipnes RS, Curnutte JT. Biological defence mechanisms: the production by leukocytes of superoxide, a potential bactericidal agent. J Clin Invest 1973;52:741-4.

[94] Klebanoff SJ. Antimicrobial mechanisms in neutrophilic polymorphonuclear leukocytes. Semin Hematol 1975;12:117-42.

[95] Gorbushin AM, lakovleva NV. Functional characterization of Littorina littorea (Gastropoda: Prosobranchia) blood cells. J Mar Biol Assoc UK 2007;87:741-6.

[96] Newton AC. Protein kinase C: structure, function, and regulation. J Biol Chem 1995;270:28495-8.

[97] Torreilles J, Gue' rin MC, Roch P. Reactive oxygen species and defense mechanisms in marine bivalves. C R Acad Sci Ser 1996;319:209-18 [in French].

[98] Nakayama K, Maruyama T. Differential production of active oxygen species in photo-symbiotic and non-symbiotic bivalves. Dev Comp Immunol 1998;22:151-9.

[99] Li H, Hu J, Xin W, Zhao B. Production and interaction of oxygen and nitric oxide free radicals in PMA stimulated macrophages during the respiratory burst. Redox Rep 2000;5:353-8. 
[100] Lambert C, Soudant P, Choquet G, Paillard C. Measurement of Crassostrea gigas haemocyte oxidative metabolism by flow cytometry and the inhibiting capacity of pathogenic vibrios. Fish Shellfish Immunol 2003;15:225-40.

[101] Bugge' MD, He' garet H, Wikfors GH, Allam B. Oxidative burst in hard clam (Mercenaria mercenaria) haemocytes. Fish Shellfish Immunol 2007;23: 188-96.

[102] Conte A, Ottaviani E. Nitric oxide synthase activity in molluscan hemocytes. FEBS Lett 1995;365:120-4.

[103] Aldieri E, Riganti C, Polimeni M, Gazzano E, Lussiana C, Campia I, et al. Classical inhibitors of NOX NAD(P)H oxidases are not specific. Curr Drug Metabol 2008;9:686-96.

[104] Stefanska J, Pawliczak R. Apocynin: molecular aptitudes. Mediat Inflamm 2008;2008:106507.

[105] Lambert C, Soudant $P$, Jegaden M, Delaporte M, Labreuche $Y$, Moal J, et al. In vitro modulation of reactive oxygen and nitrogen intermediate (ROI/RNI) production in Crassostrea gigas hemocytes. Aquaculture 2007;270:413-21.

[106] Sensi SL, Ton-That D, Sullivan PG, Jonas EA, Gee KR, Kaczmarek LK, et al. Modulation of mitochondrial function by endogenous Zn2p pools. PNAS 2003;100:6157-62.

[107] Aronis A, Melendez JA, Golan O, Shilo S, Dicter N, Tirosh O. Potentiation of Fas-mediated apoptosis by attenuated production of mitochondria-derived reactive oxygen species. Cell Death Diff 2003;10:335-44. 
Table 1 : Microscopic characterisation of the hemocyte populations of the disk abalone and the spiny top shell. Measurements were made on formalin-fixed cyto-centrifuged $\mathrm{HCMs}$ stained with Hemacolor. Values are presented as mean \pm confidence interval $(\mathrm{Cl})$; alpha $=0.05$. n, number of analysed cells; $\mathrm{C}$, Cell diameter; N, Nucleus diameter. Different letters $(\mathrm{a}-\mathrm{e})$ in rows indicate significant (ANOVA Tukey, $p<0.01$ ) differences among hemocyte populations.

\begin{tabular}{|c|c|c|c|c|c|c|}
\hline & \multicolumn{2}{|l|}{ Disk abalone } & \multicolumn{4}{|c|}{ Spiny top shell } \\
\hline & $\begin{array}{l}\text { Blast-like } \\
n=72\end{array}$ & $\begin{array}{l}\text { Hyalinocytes } \\
n=500\end{array}$ & $\begin{array}{l}\text { Blast-like } \\
n=28\end{array}$ & $\begin{array}{l}\text { Type I hyalinocytes } \\
n=380\end{array}$ & $\begin{array}{l}\text { Type II hyalinocytes } \\
n=261\end{array}$ & $\begin{array}{l}\text { Granulocytes } \\
n=22\end{array}$ \\
\hline Percentage (\%) & 3.82 & 96.18 & 4.05 & 54.99 & 37.77 & 3.18 \\
\hline Cell diameter $(\mathrm{C} ; \mu \mathrm{m})$ & $6.44^{\mathrm{a}} \pm 0.25$ & $9.39^{c} \pm 0.16$ & $7.67^{b} \pm 0.44$ & $11.55^{\mathrm{d}} \pm 0.18$ & $14.77^{\mathrm{e}} \pm 0.26$ & $15.16^{\mathrm{e}} \pm 1.19$ \\
\hline Nucleus diameter $(\mathrm{N} ; \mu \mathrm{m})$ & $5.20^{\mathrm{a}} \pm 0.16$ & $5.23^{\mathrm{a}} \pm 0.08$ & $6.30^{\mathrm{bc}} \pm 0.34$ & $6.75^{c} \pm 0.10$ & $6.23^{b} \pm 0.10$ & $6.15^{b} \pm 0.33$ \\
\hline $\mathrm{N} / \mathrm{C}$ & $0.82^{\mathrm{a}} \pm 0.01$ & $0.57^{\mathrm{b}} \pm 0.02$ & $0.83^{\mathrm{a}} \pm 0.03$ & $0.59^{b} \pm 0.01$ & $0.43^{c} \pm 0.01$ & $0.41^{c} \pm 0.02$ \\
\hline
\end{tabular}

Table 2 : Flow cytometric characterisation of the hemocyte populations of disk abalone and spiny top shell. The percentage, size (FSC) and internal complexity (SSC) of each hemocyte population from disk abalones and spiny top shells were determined on SYBR Green I positive cells fixed with 3\% formalin. Size and internal complexity are expressed in flow cytometry arbitrary units (A.U.). Values are presented as mean $\pm \mathrm{Cl}$; alpha $=0.05$. $n$, number of analysed samples. N/A, non applicable. Different letters $(a, b, c)$ in columns represent significant (ANOVA Tukey, $p<0.01$ ) differences between hemocyte populations.

\begin{tabular}{|c|c|c|c|c|c|c|}
\hline & \multirow{2}{*}{$\frac{n=18}{\text { Percentage }}$} & \multicolumn{2}{|l|}{ Disk abalone } & \multirow{2}{*}{$\frac{n=15}{\text { Percentage }}$} & \multicolumn{2}{|l|}{ Spiny top shell } \\
\hline & & Size (A.U.) & Complexity (A.U.) & & Size (A.U.) & Complexity (A.U.) \\
\hline Blast-like & $6.75 \pm 01.72$ & $390.06^{\mathrm{a}} \pm 08.95$ & $180.09^{\mathrm{a}} \pm 05.69$ & $8.94 \pm 03.16$ & $361.13^{\mathrm{a}} \pm 12.67$ & $210.68^{a} \pm 06.51$ \\
\hline Hyalinocytes & $93.25 \pm 01.72$ & $451.41^{b} \pm 10.17$ & $352.20^{\mathrm{b}} \pm 08.13$ & $74.30 \pm 06.51$ & $490.29^{b} \pm 07.65$ & $344.43^{b} \pm 09.83$ \\
\hline Granulocytes & $\mathrm{N} / \mathrm{A}$ & $\mathrm{N} / \mathrm{A}$ & $\mathrm{N} / \mathrm{A}$ & $16.76 \pm 04.43$ & $468.57^{b} \pm 21.94$ & $593.63^{c} \pm 20.59$ \\
\hline
\end{tabular}

Table 3 : Flow cytometric measurements and percentage of lysosomal-defined hemocyte subpopulations of spiny top shells. LysoTracker fluorescence intensity allowed distinction between three subpopulations amongst $T$. cornutus hemocytes (Fig. 6). Size (FSC) and internal complexity (SSC), as well as the relative percentage were determined for each LysoTracker-defined sub-populations. Values are presented as mean $\pm \mathrm{Cl}$; alpha $=0.05$. $\mathrm{n}$, number of analysed samples; A.U., flow cytometry arbitrary units. Different letters $(a, b, c)$ in columns indicate significant (ANOVA Tukey, $p<0.05$ ) differences between hemocyte populations.

\begin{tabular}{lcll}
\hline$n=10$ & Lysosomal amount (A.U.) & Size (A.U.) & Complexity (A.U.) \\
\hline LysoTracker $^{\text {Low }}$ & $34.00^{\mathrm{a}} \pm 04.73$ & $378.30^{\mathrm{a}} \pm 15.74$ & $187.84^{\mathrm{a}} \pm 11.23$ \\
LysoTracker $^{\text {Med }}$ & $77.09^{\mathrm{b}} \pm 07.68$ & $466.29^{\mathrm{b}} \pm 12.08$ & $313.51^{\mathrm{b}} \pm 25.40$ \\
LysoTracker $^{\text {High }}$ & $378.02^{\mathrm{c}} \pm 37.72$ & $535.49^{\mathrm{c}} \pm 26.25$ & $364.17^{\mathrm{c}} \pm 18.08$ \\
\hline
\end{tabular}




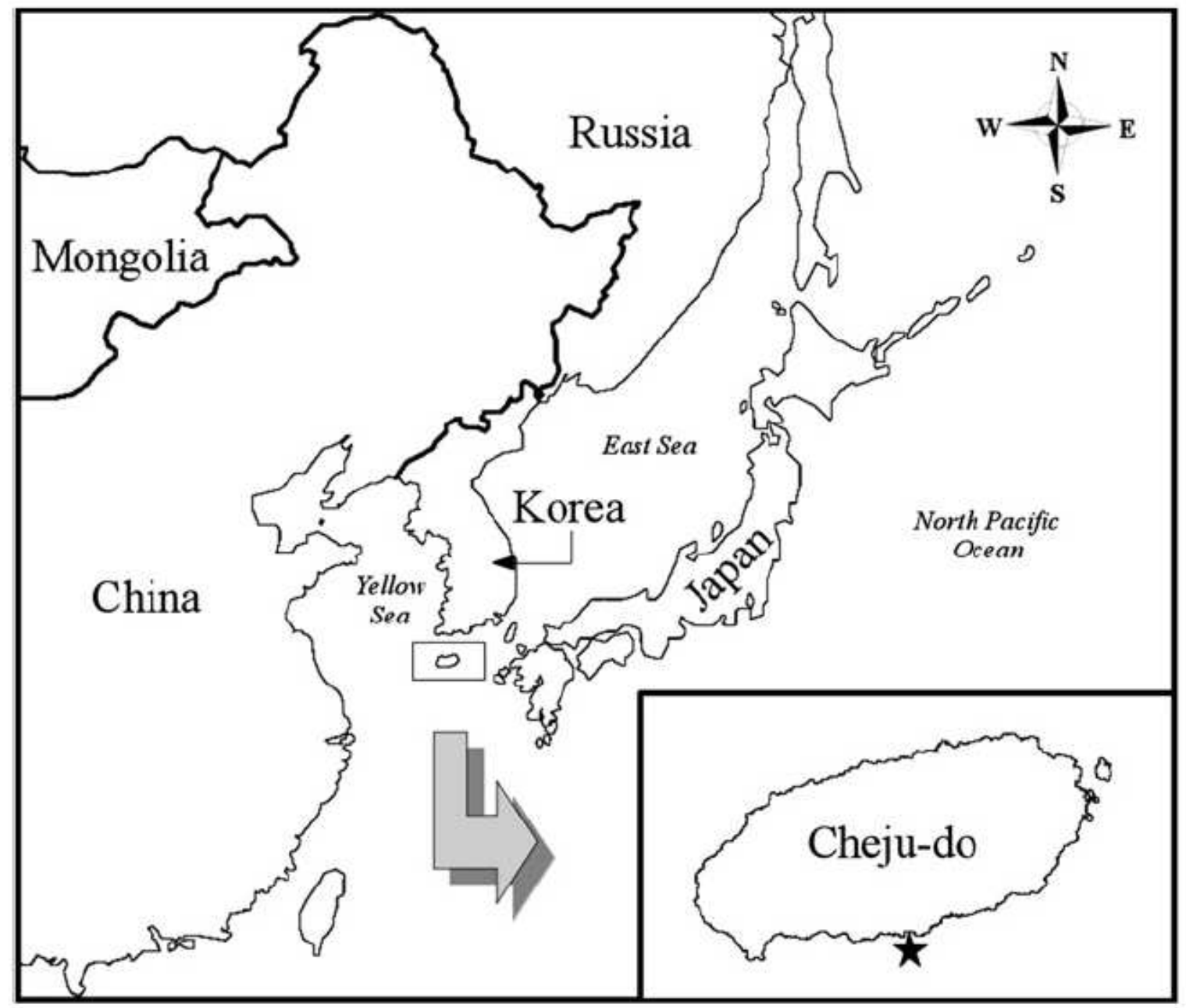

Fig. 1. Location map of the sampling site of the disk abalones (H. discus discus) and the spiny top shells ( $T$. cornutus). Disk abalones and spiny top shells were supplied from southern waters of Cheju Island, Korea (Dark star symbol). 


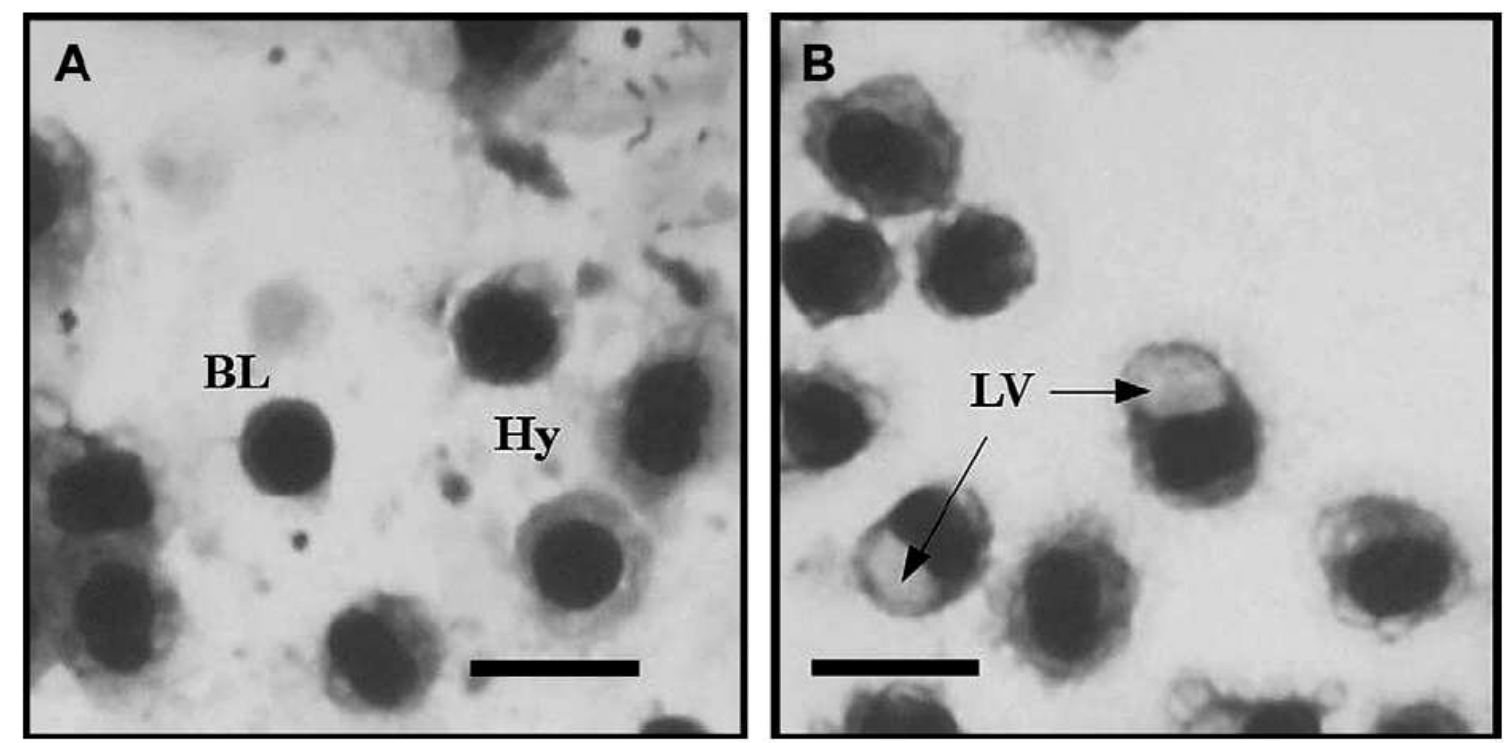

Fig. 2. Hemocytes of the disk abalone H. discus discus. Formalin-fixed cyto-centrifuged HCMs were stained with Hemacolor. (A) Two hemocyte types could be distinguished: blastlike cells and hyalinocytes. (B) Hyalinocytes from some individuals displayed large unique intra-cytoplasmic vacuole. BL, blast-like cell; Hy, hyalinocyte; LV, large vacuole. Bar: $10 \mu \mathrm{m}$.
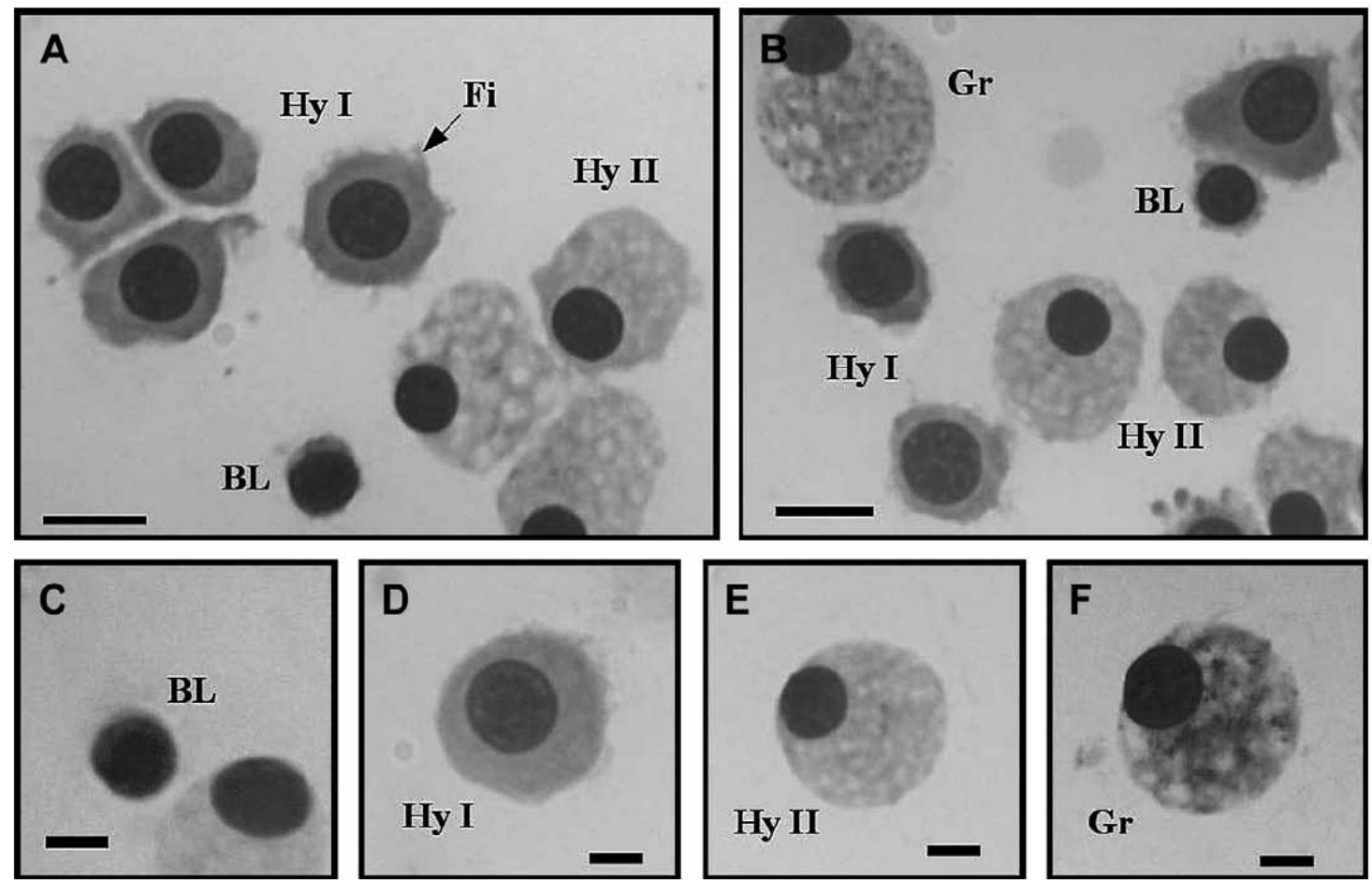

Fig. 3. Hemocytes of the spiny top shell T. cornutus. Formalin-fixed cyto-centrifuged HCMs were stained with Hemacolor. (A-B) Bar: $10 \mu \mathrm{m}$. Four hemocyte populations were distinguishable: blast-like cells, type I hyalinocytes, type II hyalinocytes and granulocytes. Type I hyalinocytes expressed thin cytoplasmic filopodia. Note the vacuolated cytoplasm of type II hyalinocytes and granulocytes; and the presence of intra-cytoplasmic granules in granulocytes. (C-F) Bar: $5 \mathrm{~mm}$. (C) Blast-like cells were small, round cells with thin cytoplasmic layer. (D) Type I hyalinocytes displayed central or slightly eccentric round nucleus. (E) Type II hyalinocytes were characterized by an eccentric nucleus and intracytoplasmic vacuoles. $(F)$ Granules were observed in the vacuolated cytoplasm of granulocytes. BL, blast-like cell; Hy I, type I hyalinocyte; Hy II, type II hyalinocyte; Gr, granulocyte; $\mathrm{Fi}$, filopodia. 
A

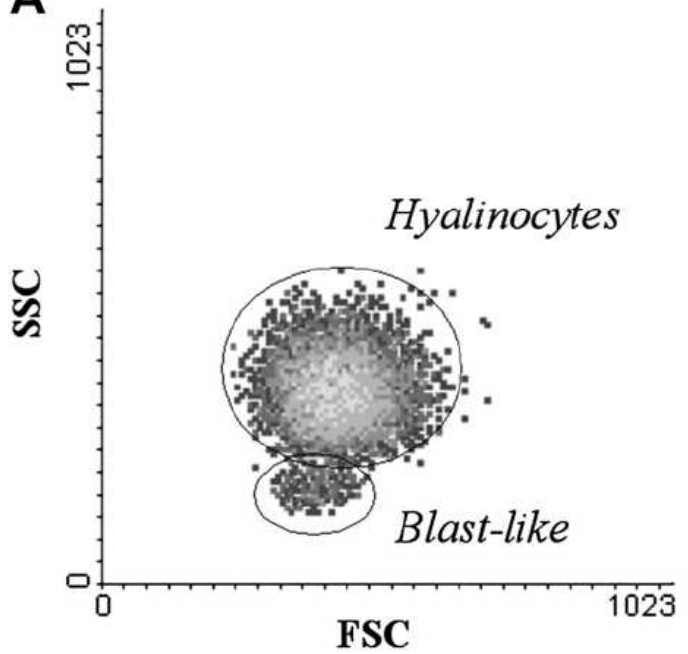

B

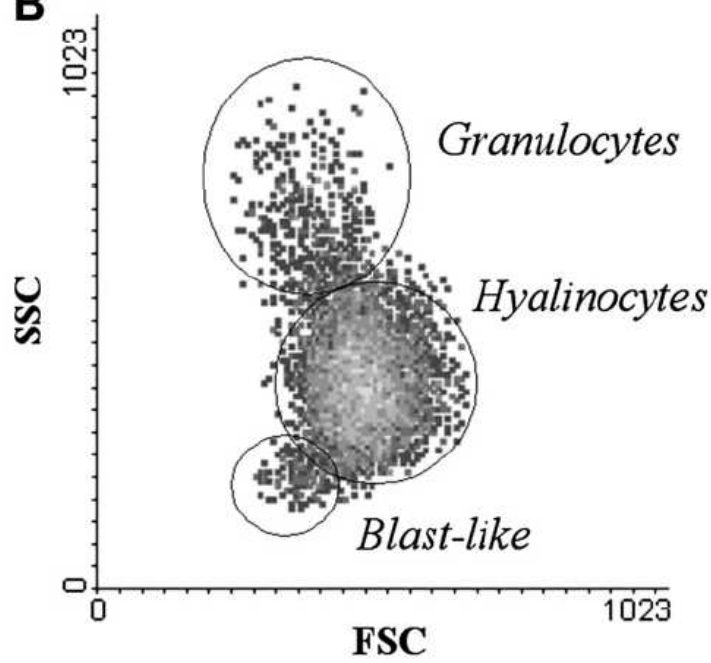

Fig. 4. Flow cytometric determination of the hemocyte populations of $H$. discus discus and $T$. cornutus. Size (FSC) against internal complexity (SSC) density plot representation of SYBR Green I positive hemocytes (3\% formalin fixation). (A) Two hemocyte populations were distinguishable in abalone: blast-like cells and hyalinocytes. (B) Three populations were observed in top shell hemolymph: blast-like cells, hyalinocytes and granulocytes. Representative results of 18 abalone and 15 top shell individuals.
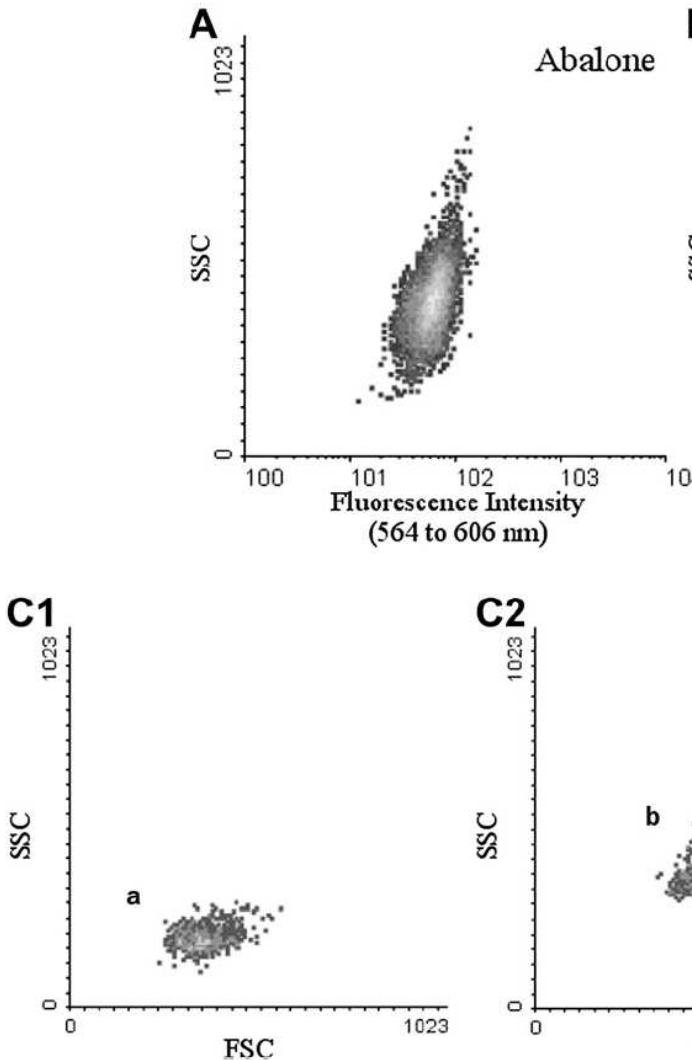

B

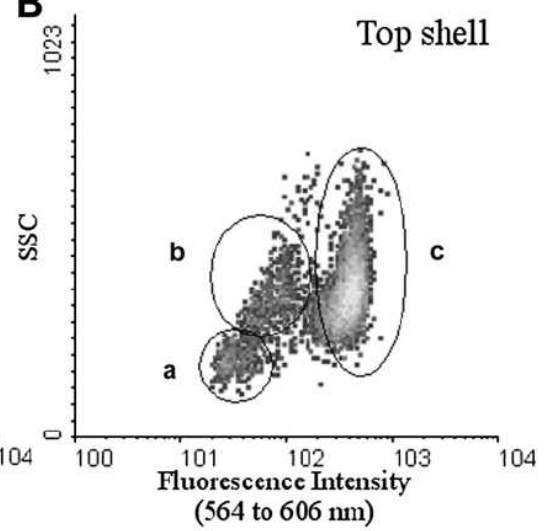

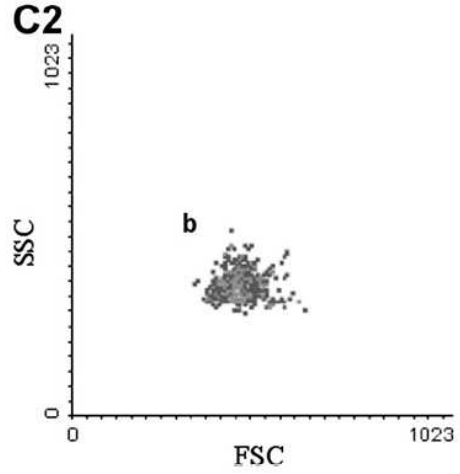

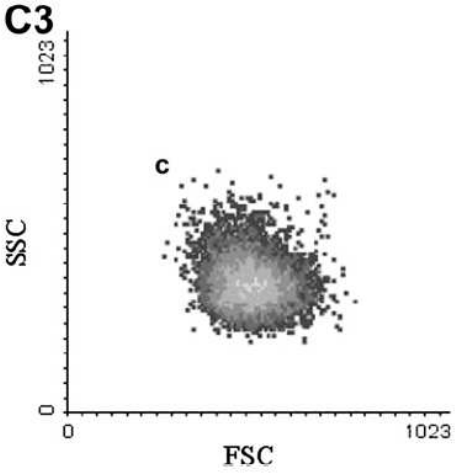

Fig. 5. Flow cytometric determination of the presence of lysosomes in the hemocytes of the disk abalone and the spiny top shell. LysoTracker fluorescent dye accumulated in lysosomal compartments of hemocytes maintained in AASH. The red fluorescence intensity relied on the amount of lysosomes inside hemocytes. Abalone hemocytes displayed an homogeneous presence of lysosomes (A). Conversely, top shell hemocytes displayed three distinguishable lysosomal amounts (B), allowing discrimination between three subpopulations containing low (a), medium (b) and high (c) amounts of lysosomes. Each lysosome-defined subpopulation was displayed under FSC (relative size) and SSC (relative complexity) parameters (C1-3). Representative results of 10 individuals from each species. 

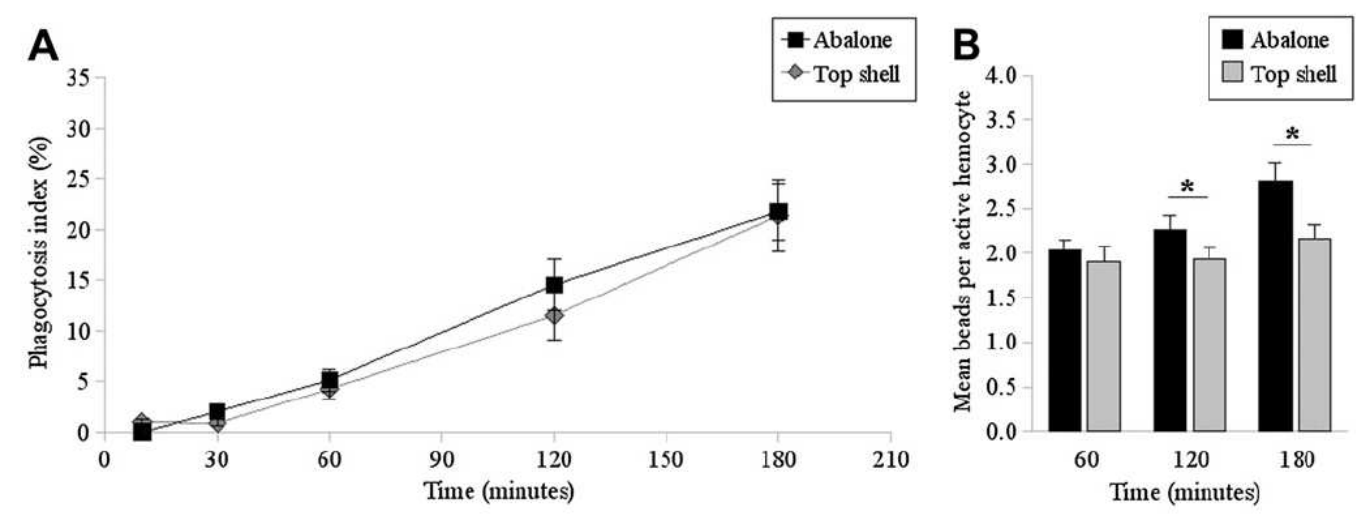

Fig. 6. Phagocytic activities of the hemocytes of the disk abalone and the spiny top shell. (A) Development of phagocytosis index (i.e., percentage of hemocytes containing at least one engulfed bead) of the hemocytes of the disk abalone and the spiny top shell over the time (from 10 to $180 \mathrm{~min}$ ). (B) Mean number of beads per phagocytic hemocyte from disk abalone and spiny top shell. Values are presented as mean $\pm \mathrm{Cl}$; alpha $=0.05$. For each time and each species, $n=20$. An asterisk indicates a significant (ANOVA, $p<0.01$ ) difference between species.
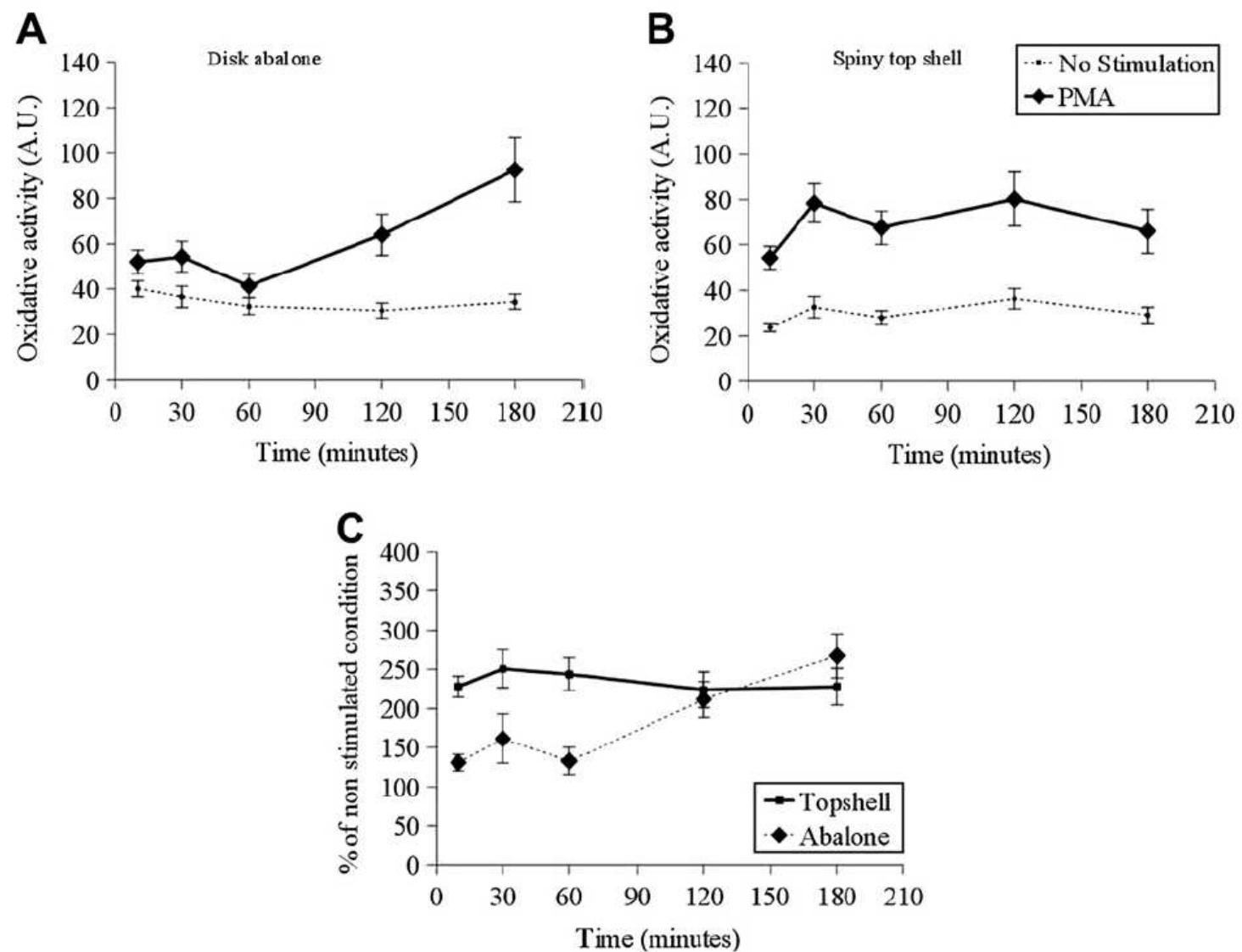

Fig. 7. Oxidative activity in the hemocytes of $H$. discus discus and $T$. cornutus. Evolution of oxidative activity, with or without PMA, was determined over the time (from 10 to $180 \mathrm{~min}$ ) in abalone (A) and top shell (B) hemocytes. (C) Effects of PMA on oxidative activity of abalone and top shell hemocytes was expressed as the percentage of non-stimulated condition (i.e., without PMA). Values are presented as mean $\pm \mathrm{Cl}$; alpha $=0.05$. For each time, $n=22$ disk abalones and $n=24$ spiny top shells. In both species and for each time, the effect of PMA stimulation was significant (ANOVA, $p<0.05$ ). 

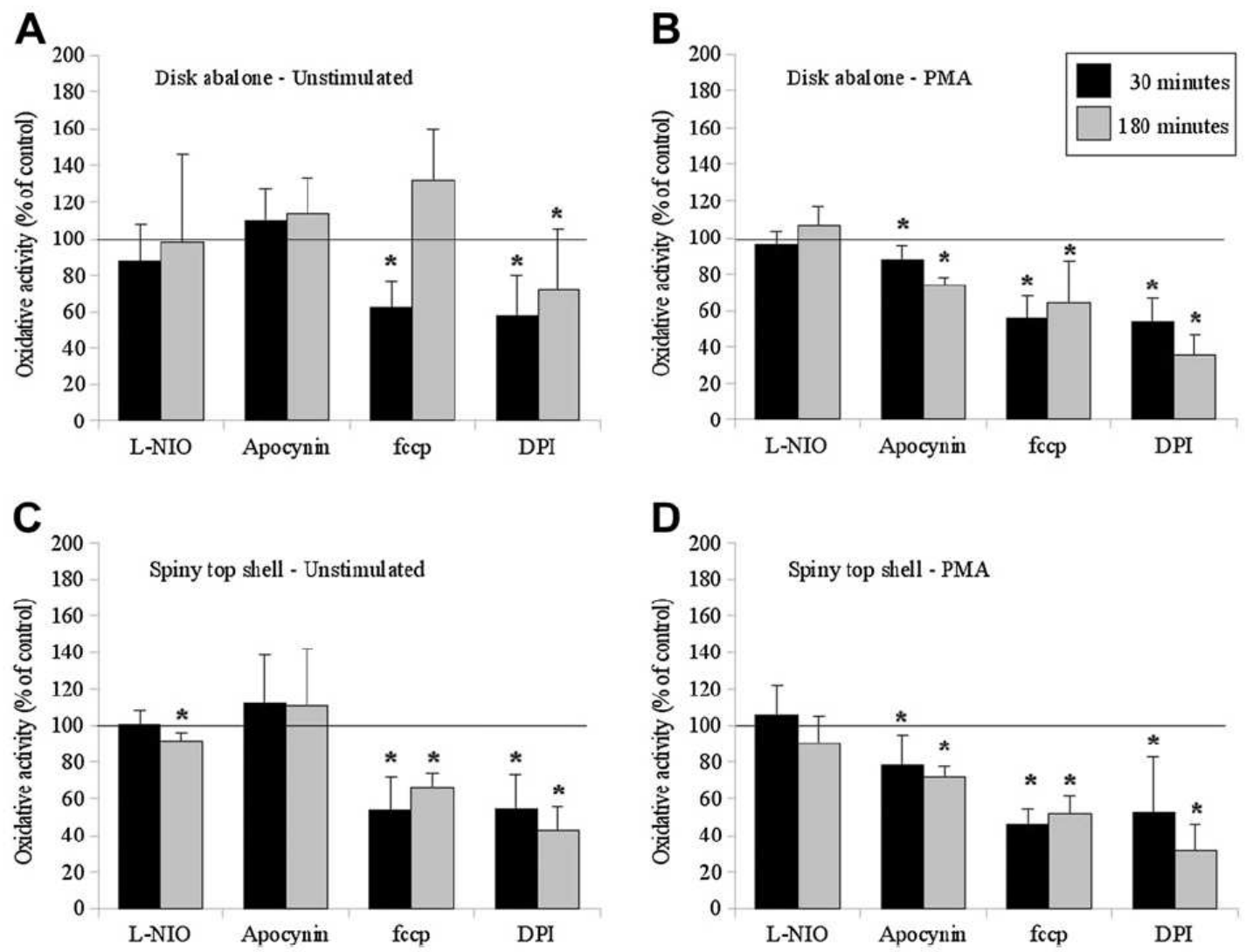

Fig. 8. Oxidative pathways in the hemocytes of the disk abalone and the spiny top shell. The effects of inhibitors were determined on the hemocytes of the disk abalone $(A-B)$ and the spiny top shell $(C-D)$, with or without PMA stimulation. The resulting oxidative activity was expressed as the percentage of control (i.e., without inhibitor). Values are presented as mean \pm $\mathrm{Cl}$; alpha $=0.05$. For each condition and each species, $n=3$. An asterisk indicates a significant (ANOVA, $p<0.05$ ) effect of the inhibitor. 